\section{Linguagem e afasia: enfrentamento de dificuldades linguísticas e recomposição da subjetividade no $\mathrm{ECOA}^{1}$ Language and aphasia: facing difficulties of language and recomposition subjectivity in the ECOA}

Nirvana Ferraz Santos Sampaio ${ }^{2}$

Universidade Estadual de Sudoeste da Bahia

Resumo: Neste trabalho, investigamos o Espaço de Convivência entre Afásicos e não Afásicos (ECOA), do Centro de Convivência e Intervenção em Neurolinguística (CeCIN/LAPEN/UESB). Defendemos: a) que, nas situações comunicativas e eventos comunicativos em que se engajam os sujeitos com lesões cerebrais no ECOA, a língua(gem) apresenta-se constitutivamente incompleta, falha e heterogênea, características da ordem própria e estrutural da língua quando usada também pelos sujeitos sem lesões cerebrais; b) que em meio a práticas significativas, organizadas em torno de situações cotidianas que propiciam a atividade efetiva de linguagem em uma atuação conjunta entre sujeitos e pesquisadores, há eficácia nas interações. Essa investigação é feita por meio do acompanhamento longitudinal, em sessões semanais. Os atendimentos fundamentam-se nos estudos de Freud (1891); Jakobson (1954; 1956); Luria (1979) e Coudry (1986/1988; 2008; 2010). Os sujeitos afásicos que participam do ECOA são levados a enfrentar a afasia agindo com e sobre a linguagem, a partir de repertório comunicativo variado que inclui recursos linguísticos e não linguísticos, em diferentes práticas sociais. Dessa forma, o ECOA promove ações que inter-relacionam a teoria e a prática na área de neurolinguística, promove ações processuais e contínuas de caráter social, cultural, educativo e científico, viabilizando a produção de conhecimento nessa área e, ao mesmo tempo, articulando linguagem e subjetividade juntamente com sujeitos com lesões cerebrais no enfrentamento das dificuldades linguísticas e recomposição da subjetividade. Este trabalho está vinculado ao financiamento do CNPq processo 471384/2010-0 e ao financiamento de projetos de extensão Edital 121/2011 UESB.

Palavras-chave: Linguagem. Subjetividade. Afasia.

Abstract: In this paper, we investigate the "Espaço de Convivência entre Afásicos e não Afásicos (ECOA)", in the "Centro de Convivência e Intervenção em Neurolinguística (CeCIN/LAPEN/UESB)”. We argue that: a in communicative situations and communicative events in which the brain damage subjects at CCA are engaged, the language is incomplete, defective and heterogeneous, characteristics considered as being part of the language proper order and structure when used by subjects without brain damage as well, b) that in the midst of significant practices, organized around everyday situations that provide the activity of language in an effective joint action between subjects and researchers, there are
${ }^{1}$ Este trabalho está vinculado ao financiamento do CNPq processo 471384/2010-0 e aо financiamento de projetos de extensão Edital 121/2011 UESB.

${ }^{2}$ Doutora em Linguística. Professora do Programa de Pós-Graduação em Linguística da Universidade Estadual do Sudoeste da Bahia. E-mail: <nirvanafs@terra. com.br> 
effective interactions. This research is done through the longitudinal attendance, in weekly sessions. The sessions are based on studies of Freud (1891), Jakobson (1954, 1956), Luria (1979) and Coudry (1986/1988, 2008, 2010). The aphasic subjects participating in the ECOA are taken to cope with aphasia with and acting on language from varied communicative repertoire that includes non-linguistic and linguistic resources, in different social practices. Thus, the ECOA promotes activities that interrelate theory and practice in the field of neurolinguistics, promotes procedural actions and continuous social, cultural, educational and scientific, enabling the production of knowledge in this área, and at the same time, articulate language and subjectivity along with brain-injured individuals in coping with language difficulties and restoration of subjectivity. This work is linked to funding from CNPq process 471384/2010-0.

Keywords: Language. Subjectivity. Aphasia.

\section{Introdução}

O objetivo deste artigo é apresentar os resultados relacionados à pesquisa e à extensão em Neurolinguística na Universidade Estadual do Sudoeste da Bahia (UESB). No Laboratório de Pesquisa e Estudos em Neurolinguística e no Centro de Convivência e Intervenção em Neurolinguística (LAPEN/ CECIN/ UESB), desenvolvemos pesquisas direcionadas à avaliação e ao seguimento longitudinal de bebês, crianças, jovens e adultos que apresentam dificuldades no processo de aquisição da linguagem (oral/escrita) ou mesmo de crianças que receberam um diagnóstico que compromete tal processo e sua permanência na escola (dislexia, transtorno do déficit de atenção com hiperatividade etc.); crianças, jovens e adultos que sofreram episódio neurológico ou algum tipo de degeneração comprometendo de alguma forma seu funcionamento com e na linguagem (afasias e demências) e acompanhamento e intervenção de bebês e/ou crianças com deficiência mental (mais especificamente a síndrome de Down).

Neste recorte, apresentamos alguns resultados do Espaço de Convivência entre Afásicos e não Afásicos (ECOA), do CECIN. Verifica-se que o sujeito afásico é um ser profundamente transformado, não somente por seus problemas de linguagem, mas também pelas consequências destes sobre sua vida, quer tenha ou não consciência disso. Dessa forma, defendemos: a) que, nas situações comunicativas e eventos comunicativos em que se engajam os sujeitos com lesões cerebrais no ECOA, a língua(gem) apresenta-se constitutivamente incompleta, falha e heterogênea, características da ordem própria e estrutural da língua quando usada também pelos sujeitos sem lesões cerebrais; b) que, em meio a práticas significativas, organizadas em torno de situações cotidianas que propiciam a atividade efetiva de linguagem em uma atuação conjunta entre 
sujeitos e pesquisadores, há eficácia nas interações. Nas próximas sessões, abordaremos a constituição teórico-metodológica deste artigo, a coleta dos dados e a análise e discussão que levam em consideração o enfrentamento da afasia e a recomposição da subjetividade de sujeitos com diagnóstico médico de afasia.

\section{Questões teórico-metodológicas}

As pesquisas desenvolvidas no ECOA são realizadas por meio do acompanhamento longitudinal, em sessões semanais. Os atendimentos fundamentam-se nos estudos de Freud (1891); Jakobson (1954; 1956); Luria (1979) e Coudry (1986/1988; 2008; 2010). Os sujeitos afásicos que participam do ECOA são levados a enfrentar a afasia agindo com e sobre a linguagem, a partir de repertório comunicativo variado que inclui recursos linguísticos e não linguísticos, em diferentes práticas sociais. Dessa forma, o ECOA promove ações que inter-relacionam a teoria e a prática na área de neurolinguística, promove ações processuais e contínuas de caráter social, cultural, educativo e científico, viabilizando a produção de conhecimento nessa área.

Para o acompanhamento dos sujeitos direcionados ao ECOA por neurologistas, parte-se do seguinte conceito:

A afasia se caracteriza por alterações de processos linguísticos de significação de origem articulatória e discursiva (nesta incluídos aspectos gramaticais) produzidas por lesão focal adquirida no sistema nervoso central, em zonas responsáveis pela linguagem, podendo ou não se associarem a alterações de outros processos cognitivos. Um sujeito é afásico quando, do ponto de vista linguístico, o funcionamento de sua linguagem prescinde de determinados recursos de produção ou interpretação. (COUDRY, 1988, p. 5).

A afasia problematiza a subjetividade, visto que o mal-estar do sujeito em sua fala, o estranhamento da sua fala e a percepção do outro (diante da "fala afásica") indiciam a relação subjetividade e linguagem e, ao mesmo tempo, articulam linguagem e subjetividade. Nesse sentido, torna-se um desafio para os pesquisadores que trabalham com o enfrentamento das dificuldades linguísticas e recomposição da subjetividade dos sujeitos afásicos. Critica-se, dessa forma, o olhar que reduz todos os afásicos a um só modelo de "paciente".

Essa crítica é estabelecida com base em uma concepção abrangente de linguagem (FRANCHI, 1977/92), integrada aos postulados neuropsicológicos de Luria (1977) e à análise crítica aos estudos localizacionistas desenvolvida por Freud (1891), juntamente com os conceitos de representação-palavra e de representação-objeto, de Freud, como uma forma de compreender o quadro complexo das afasias, bem 
como para encaminhar seu processo de reestruturação. Os estudos realizados por Jakobson (1955/1970; 1956/1975) - que caracteriza a afasia como um problema de linguagem que pode levar a uma redistribuição das funções linguísticas - recebe destaque em nosso trabalho, visto que Jakobson propôs uma classificação de acordo com os "eixos" de organização da linguagem, a partir de Saussure (1916): o paradigmático, que estaria comprometido nos afásicos com dificuldades na seleção de elementos linguísticos dentro de uma mesma categoria; e o sintagmático, relacionado à sua combinação, fonemas em morfemas, estes em palavras e palavras em sentenças. Assim, os pesquisadores do ECOA reinterpretam os quadros afásicos dos sujeitos do grupo e contextualizam as intervenções orientadas para o uso da linguagem por meio de um conjunto de dadosachados (COUDRY, 1996) que envolvem a oralidade, a escrita e a leitura.

No estudo do neurologista Freud (1891) "Zur Auffassung der Aphasien”, há uma ruptura teórica com o pensamento localizacionista hegemônico da neurologia no final do século XIX. Freud elabora um estudo crítico das teorias neurológicas vigentes, sobretudo as elaboradas por Meynert, Lichtheim, Grashey, Wernicke. Ele focaliza seu estudo na afasia com atenção à patologia do funcionamento da linguagem e da língua e destaca a ocorrência das parafasias. O modelo de aparelho de linguagem, baseado nos laços entre a representação-palavra e a representação-objeto, apresentado por Freud, estabelece consequências teóricas, clínicas e metapsicológicas ao longo de sua obra e ganha destaque nas pesquisas do LAPEN.

O trabalho de Alexander Ramanovich Luria (1902-1977), por outro lado, a partir de estudos de pacientes com lesão do sistema nervoso central, tem relevância nas pesquisas, acompanhamentos e trabalhos desenvolvidos pelo ECOA/CECIN/LAPEN, visto que Luria demonstrou que as funções superiores organizam-se em sistemas funcionais complexos, ou seja, não há participação de apenas uma área específica do cérebro, mas sim da ação de várias áreas. Além disso, Luria preconizou que o cérebro está organizado em três unidades funcionais principais, cuja atuação "em concerto" possibilita qualquer tipo de atividade mental.

Jakobson (1954) esclarece que a fala normal é caracterizada por uma bipolaridade em que seleção e combinação funcionam adequadamente, por um lado, e, por outro lado, a fala patológica do afásico é caracterizada pela ruptura dessa bipolaridade. Dessa forma, se estabeleceria uma fala unipolar, na qual o afásico privilegiaria um eixo em detrimento do outro. Os trabalhos desenvolvidos por Coudry, desde os anos 80, defendem que Jakobson avançou muito na compreensão das dificuldades linguísticas das afasias e também nas questões relativas à sua semiologia, uma vez que os fenômenos linguísticos passaram a ter primazia, ao contrário das abordagens que privilegiam a lesão e a colocam numa relação direta com os sinais linguísticos apresentados. 
No decorrer da pesquisa, não contemplamos somente o estudo da forma linguística, mas também a função da linguagem. Segundo Benveniste (1963):

A linguagem reproduz a realidade. Isso deve entender-se da maneira mais literal: a realidade é produzida novamente por intermédio da linguagem. Aquele que fala faz renascer pelo seu discurso o acontecimento e a sua experiência do acontecimento. Aquele que o ouve apreende primeiro o discurso e através desse discurso, o acontecimento reproduzido. Assim a situação inerente ao exercício da linguagem, que é a da troca e do diálogo confere ao ato de discurso dupla função: para o locutor, representa a realidade; para o ouvinte, recria a realidade. Isso faz da linguagem o próprio instrumento da comunicação intersubjetiva (...) a ‘forma' do pensamento é configurada pela estrutura da língua. E a língua por sua vez revela dentro do sistema das suas categorias a sua função mediadora. Cada locutor não pode propor-se como sujeito sem implicar o outro, o parceiro que, dotado da mesma sintaxe de enunciação e igual maneira de organizar o conteúdo. A partir da função linguística, e em virtude da polaridade eu: tu, indivíduo e sociedade não são mais termos contraditórios, mas termos complementares. (BENVENISTE, 1963, p. 26).

De acordo com Benveniste (1970, p.14), a enunciação é o ato de o sujeito se apropriar da língua e colocá-la em funcionamento. Com isso, tem-se como resultado o discurso, sendo o produto dessa apropriação. Benveniste diz que só é possível compreender a língua como um todo através da enunciação, pois antes da enunciação, segundo ele, a língua não é senão possibilidade da língua. É nessa perspectiva que estudamos a relação entre linguagem e cérebro e, nesse sentido, é preciso olhar para a linguagem em funcionamento, isto é, através da enunciação. Em outros termos, estamos aqui reconhecendo que há um funcionamento tanto em termos gramaticais (língua) quanto nos textos (discursivo), e que ambos entrelaçam-se na linguagem, oral e escrita, em funcionamento.

Baseamo-nos em Franchi (1977, p.12) quando ele afirma que

Concebemos assim a linguagem como um trabalho que 'dá forma' ao conteúdo variável de nossas experiências, trabalho de construção e retificação do 'vivido', que ao mesmo tempo constitui o sistema simbólico mediante o qual se opera sobre a realidade e constitui a realidade como um sistema de referências em que aquele se torna significativo.

Dessa forma, considerando a linguagem enquanto ação, somos conduzidos a pensar a linguagem como um trabalho daquele que atua sobre a própria linguagem. Como flagrar os dados em ação? 


\section{Sobre a coleta e análise de dados}

A maior parte dos estudos sobre afasia tem valorizado análises quantitativas, baseadas em testes-padrão. Esses testes buscam uma generalização dos dados, ligada à noção de um sujeito-padrão. Coudry e Possenti (1983), criticando esse tipo de avaliação, abordaram a utilização de teorias linguísticas na avaliação de linguagem de sujeitos afásicos de maneira parcial, basicamente considerando tarefas metalinguísticas a que são submetidos. Os autores sugerem um outro modo de avaliar os discursos patológicos a partir da Teoria da Enunciação.

Mecacci (1987) critica a metodologia que seleciona grupos distintos de indivíduos, geralmente constituídos de estudantes universitários, homens brancos da Europa Ocidental, para estudar historicamente o cérebro. Os estudos que seguem esse tipo de metodologia tentam viabilizar uma ideia de homogeneidade que tem ajudado a constituir a própria ideia de cérebro humano como livre de qualquer referência histórica e individual, e é essa a critica de Mecacci. Ele afirma que com esse tipo de estudo: "Constroem-se uma lógica universal, uma linguagem, uma memória e um pensamento válidos para a comunicação entre máquinas” (MECACCI, 1987, p.147). Dessa forma, temos construtos sobre a linguagem separados de seu contexto concreto e que pouco se relacionam com o que de fato ocorre na linguagem em funcionamento.

Em o "Diário de Narciso: Discurso e afasia”, tese de doutorado defendida por Maria Irma Hadler Coudry, em 1986, no Instituto de Estudos da Linguagem (IEL-Unicamp), que em 1988 foi publicada em forma de livro, Coudry analisa os casos dos sujeitos N, P, e L, apresentando-os como sujeitos que, embora afásicos, exercem sua subjetividade na linguagem.

Outros estudos, no âmbito da Linguística, formularam também questionamentos em relação ao emprego de testes como metodologia para avaliação da linguagem de sujeitos afásicos, dentre eles podemos citar os trabalhos de Coudry; Possenti (1983) e Coudry (1986/88), Novaes-Pinto (1992,1999); Gregolin-Guindaste (1996); Freitas (1997); Fedosse (2000, 2008); Mármora (2000); Freire (2005); Ishara (2008).

Em nossos estudos, a análise dos dados é feita qualitativamente, uma vez que consideramos essa forma como a mais apropriada para estabelecer as bases explicativas para os fenômenos de linguagem e da subjetividade.

Consideramos que a escolha pelo acompanhamento longitudinal (individualmente ou em grupo ${ }^{3}$, em encontros semanais de 1 hora) de sujeitos afásicos inseridos em uma perspectiva discursiva da afasia, trata-se de uma opção teórico-metodológica fundamental para o entendimento da linguagem em funcionamento nos sujeitos em questão. Nessa perspectiva, verifica-se a linguagem em uso, expressando a relação entre sujeito e linguagem ou, em outros termos, entre linguagem, práxis e percepção.

${ }^{3}$ Consultar o estudo de Sampaio (2006) que descreve $o$ trabalho em grupo que é realizado no Centro de Convivência de afásicos do Instituto de Estudos da Linguagem, UNICAMP. 
Recorremos ao estudo longitudinal para que se possa dar visibilidade as instabilidades linguísticas que ocorrem no mesmo sujeito em momentos diferentes, bem como as inconstâncias existentes dentro do próprio fenômeno da afasia entendidas como decorrentes da própria natureza da linguagem. É dentro dessa perspectiva que a metodologia de estudo longitudinal permite observar as mudanças na natureza das relações do sujeito com a língua e com os parâmetros antropoculturais (com base em Franchi, 1977) e, como se destaca nesta pesquisa, as marcas da língua presentes nas produções.

Coudry (2002) afirma que há linguagem na afasia quando há sujeito e que afásico e não afásico partilham de um sentimento/atitude comum de incompletude frente à linguagem e à língua. A autora questiona "Quem nunca passou por situações de se sentir mais incompleto do que usualmente, hesitando, retomando, interrompendo, tendo menos controle sobre o que diz?” e afirma que na afasia podem ocorrer várias dessas dificuldades, e outras, com a diferença de ser trabalhoso para o sujeito afásico sair desse mau momento, que se repete em várias situações e que não é tão passageiro (como pode ocorrer com pessoas não afásicas). São situações difíceis que o afásico enfrenta, sobretudo levando em conta o grau de tolerância zero que se tem hoje em dia para com os "normais".

Em resumo, considera-se que o funcionamento da linguagem se apresenta sob a forma do que Jakobson chama de uso habitual da linguagem, tendo lugar em meio a práticas discursivas significativas para um sujeito que participa de uma comunidade linguística.

Trabalhamos com os princípios teórico-metodológicos da Neurolinguística Discursiva (ND) em que o dado é tomado como dado-achado, que é o resultado das práticas discursivas e não está presente em práticas avaliativas e experimentais realizadas dentro de outras perspectivas em que os dados aparecem como evidência ou exemplo (conferir COUDRY, 1996). O dado-achado, segundo Coudry (1996, p. 183), "é produto da articulação de teorias sobre o objeto que se investiga com a prática de avaliação e acompanhamento clínico dos processos linguísticos-cognitivos”.

Esses dados são retirados a partir dos procedimentos metodológicos (também utilizados na prática (clínica) com a linguagem por Coudry (1986/1988)), tais como: o conhecimento mútuo e interação com a família, o uso de agenda, apresentação de pessoas mediante a organização de um álbum de retratos, leitura de jornal, uso de caderno de atividades, uso do computador, comentários sobre fatos de interesse dos interlocutores, situações e cenas do dia-a-dia (dramatizadas em sketches), interação em jogos de mesa, comentário de filmes (após sessão cinema), entre outras atividades. Os dados são obtidos em diferentes situações dialógicas e práticas discursivas, na medida em que a interlocução, as relações discursivas e as condições de produção dos enunciados aparecem como 
constitutivas dos processos de significação (COUDRY, 1986/1988), sendo necessário estabelecer a relação de um enunciado com outros enunciados para que as produções possam ser analisadas e compreendidas. Dessa forma, são dados obtidos de forma observacional-participativa, longitudinal, descritiva, qualitativa e interpretativa. Assim, nas interpretações, ou seja, nas análises, estão sempre presente os pressupostos da ND, vertente teórico-metodológica constituída por um conjunto de teorias e práticas, "cuja concepção de linguagem, ao contrário de uma visão organicista, concebe língua, discurso, cérebro e mente como construtos humanos que se relacionam.” (COUDRY, 2008, p. 16).

As sessões são registradas em áudio (gravador de voz digital) e/ ou vídeo (handycam DCR-SR 47), fator fundamental nessa pesquisa, já que consideramos relevante o momento da enunciação, as condições de produção e a relação da linguagem com outros sistemas. Posteriormente, esses registros são transcritos seguindo as normas (modelo de registro) de transcrição do Banco de Dados em Neurolinguística (BDN) elaboradas por Coudry e seu grupo no Projeto Integrado em Neurolinguística: avaliação e banco de dados (CNPq: 521773/95-4).

Ressaltamos a importância dada à leitura das transcrições dos diálogos ocorridos entre o sujeito afásico e o seu interlocutor, pois os investigadores se voltam para a análise da interpretação ou, ainda, do efeito da fala do outro, sobre os arranjos significantes da fala do afásico. Procuramos dizer algo sobre essa fala (mesmo com lacunas, hesitações, fragmentos), no sentido de vinculá-los a textos ausentes, indicativos de que há um sujeito na/da linguagem em funcionamento.

\section{Defrontar-se com a afasia, enfrentá-la e se recompor como sujeito da linguagem}

A afasia pode ser um sintoma ou uma sequela. Um sintoma que indica que algo não está bem, há uma desordem neurológica que deve ser investigada. A afasia pode ser uma consequência de lesões cerebrais provocadas por traumatismo cranioencefálico, tumoração ou acidentes vasculares cerebrais (AVC). Ao se defrontar com a afasia, o afásico pode se sentir prisioneiro de si mesmo, ou seja, sabe o que quer dizer, mas não conseguir colocar em palavras, como, por exemplo, "aqui , paqui ô - apontando para a cabeça e para a boca”, diz OJ, um dos sujeitos que participam do ECOA, em uma sessão, e, em outra sessão, em um momento de frustração e instabilidade, desabafa: "Oh, minha Nossa Senhora, eu não estou podendo falar!”

Frequentemente, as dificuldades de falar impedem que o afásico seja capaz de contar como foi o dia, de dizer como se sente, e até de explicar onde sente dor. Isso impede que consigam ter rotinas que antes 
eram absolutamente comuns e banais, como, por exemplo, ir ao comércio sozinho ou ir ao trabalho. Essas questões podem levar ao desespero, à frustração, ao isolamento e até à agressão física, afetam a autoestima, modificam a autonomia, a estrutura familiar, profissional e social.

O dado a seguir foi retirado do primeiro encontro no ECOA entre RG (34 anos, que, segundo diagnóstico médico, apresenta afasia como sequela de um Acidente Vascular Cerebral Isquêmico (AVCi) decorrente de trombose de seio venoso) e MB (22 anos, segundo diagnóstico médico, apresenta afasia como sequela de um Acidente Vascular Cerebral Isquêmico (AVCi) na região têmpro parietal esquerda). No trecho, RG apresenta a sua história para o grupo e MB identifica-se com a história.

Situação comunicativa: 19/08/2011

Quadro 1 - Dado 1 Essa menina sou eu. 4 / Dado 2 Encarnou aqui e eu viva ainda

\begin{tabular}{|c|c|c|c|}
\hline $\begin{array}{l}\text { Sigla do } \\
\text { locutor }\end{array}$ & Transcrição & $\begin{array}{l}\text { Observação sobre } \\
\text { as condições de } \\
\text { produção de processos } \\
\text { alternativos de } \\
\text { produção não verbais }\end{array}$ & $\begin{array}{c}\text { Observação sobre } \\
\text { as condições de } \\
\text { produção de processos } \\
\text { alternativos de } \\
\text { produção verbais }\end{array}$ \\
\hline RG & $\begin{array}{l}\text { Pra você ver como é difícil. É fato } \\
\text { de você, é, uma pessoa que sabe, } \\
\text { tá tudo lá, mas eu não consigo } \\
\text { expressar, sabe? E se estiver muito } \\
\text { nervosa aí. Eu falo até com Iic, eu } \\
\text { falei assim, vocês ainda não me } \\
\text { viram ainda nos meus picos da } \\
\text { ansiedade. Porque na verdade isso } \\
\text { tudo é a ansiedade. Na verdade meu } \\
\text { médico já falou, RG seu problema é } \\
\text { ansiedade. Tanto é que esse, esse. }\end{array}$ & & \\
\hline MB & $\begin{array}{l}\text { Ele também já me falou isso. Que } \\
\text { médico? Que médico? }\end{array}$ & & \\
\hline RG & Esse. Dr N. & & Risos \\
\hline MB & Tu é eu, é? Essa menina sou eu. & & \\
\hline Iic & Essa menina sou eu. & & Risos \\
\hline MB & Encarnou aqui e eu viva ainda. & & \\
\hline RG & Será por que que essa? & & Risos \\
\hline Iic & Ah, MB, emociona a gente. & & \\
\hline MB & $\begin{array}{l}\text { Eu não vou falar, não. Você já está } \\
\text { falando por mim e por você. Só } \\
\text { meu caso que foi diferente. }\end{array}$ & & \\
\hline Ins & Vai falar sim, uai. & & \\
\hline
\end{tabular}

${ }^{4}$ Transcrição de Iva Ribeiro Cota. Aluna do Mestrado em Linguística do Programa de Pós-Graduação em Linguística da UESB.

Verificamos que MB, ao ouvir o relato de RG, sobre a sua condição atual no mundo e na linguagem, afirma “Tu é eu, é? Essa menina sou eu.” ou em "Encarnou aqui e eu viva ainda". Há uma identificação com os déficits linguísticos apresentados por RG, há um reconhecimento, uma aceitação e 
um alívio. Entretanto, essa aceitação não é passiva e de resignação, quando MB diz "Eu não vou falar, não. Você já está falando por mim e por você. Só meu caso que foi diferente.”, o diferente precisa ser narrado, e MB, em outro momento, também conta a sua história e sobre a condição de sujeito de linguagem que passou a exercer, visto que retornou à faculdade, continua os seus estudos e observa as similaridades e as diferenças entre os casos nas sessões em grupo. Desde os primeiros encontros com MB, conversamos sobre as possibilidades de (re)construir sua linguagem utilizando recursos do próprio sistema linguístico (as associações) e de outro meios, como processos significativos não verbais, para driblar as suas dificuldades. Abaixo, apresentamos uma dificuldade e um argumento para a troca efetuada por MB, vejamos,

Situação comunicativa: 19/08/2011

Quadro 2 - Dado 3 Apicultura - Acupuntura ${ }^{5}$

\begin{tabular}{|c|c|c|c|}
\hline $\begin{array}{c}\text { Sigla do } \\
\text { locutor }\end{array}$ & Transcrição & $\begin{array}{c}\text { Observação sobre } \\
\text { as condições de } \\
\text { produção de processos } \\
\text { alternativos de } \\
\text { produção não verbais }\end{array}$ & $\begin{array}{c}\text { Observação sobre } \\
\text { as condições de } \\
\text { produção de processos } \\
\text { alternativos de } \\
\text { produção verbais }\end{array}$ \\
\hline MB & $\begin{array}{c}\text { Eu vi que RG faz } \\
\text { apicultura }\end{array}$ & Apontando para a orelha. & \\
\hline Itp & Acupuntura? & $\begin{array}{c}\text { Ah é eu vi apicultura } \\
\text { na entrada da UESB }\end{array}$ & $\begin{array}{c}\text { Aponta para a entrada da } \\
\text { UESB. }\end{array}$ \\
\hline MB & \multicolumn{3}{|c|}{} \\
\hline
\end{tabular}

5 Transcrição de Tamiles Paiva Novaes. Aluna do curso de Letras Modernas da UESB. Bolsista de Iniciação Científica do CNPq

Constatamos aqui um fato recorrente na fala de MB, qual seja: a parafasia (substituições fonológicas, lexicais, e semânticas) recorrente na fala desse sujeito que acompanhamos. Esse dado foi obtido em situações dialógicas no ECOA. MB produz uma parafasia trocando a palavra "acupuntura" por "apicultura”. Nota-se que a troca ocasionada pelos sons semelhantes e por uma situação anterior ao momento da situação interativa. MB se coloca na linguagem, ao contrário do que se considera na tradição afasiológica. Apesar das dificuldades e limites consequentes da afasia, o sujeito afásico aprende a conviver com tais limites, observa-se aqui a importância de interações que se baseiam em relações discursivas por meio do uso social da linguagem. Dessa forma, somente na interação percebemos e compreendemos a associação feita por MB ao substituir a palavra alvo por uma outra. Observa-se aqui a importância da cooperação de Itp que estabelece a associação entre o que ouviu e o que MB pretendia dizer.

O dado abaixo apresenta a dificuldade de OJ, 34 anos, que, segundo diagnóstico médico, apresenta afasia como sequela de um Acidente Vascular Cerebral Isquêmico. OJ é alfabetizado, mas está impossibilitado também de escrever por conta da hemiplegia (paralisia de um dos lados do 
corpo), sequela deixada pelo AVCi. Tendo o lado direito paralisado e sendo destro, não escrevia. Sugerimos a OJ que tentasse treinar para escrever com a mão esquerda e ele concordou, sabendo que no momento não dispõe de muitos recursos para (re)construir sua linguagem. Uma semana depois, na sessão seguinte, OJ volta assinando o próprio nome com ótimo desempenho. A seguir, o episódio em que OJ se interessa em escrever o nome da filha, vejamos,

Situação comunicativa: 19/08/201

Quadro 3 - Dado 4 A escrita ${ }^{6}$

${ }^{6}$ As transcrições dos quadros 3 e 4 foram feitas por

\begin{tabular}{|c|c|c|c|}
\hline $\begin{array}{l}\text { Siglas do } \\
\text { locutor }\end{array}$ & Transcrição & $\begin{array}{l}\text { Observação sobre as } \\
\text { condições de produção de } \\
\text { processos alternativos de } \\
\text { produção não verbais }\end{array}$ & $\begin{array}{l}\text { Tipo de processo } \\
\text { alternativo utilizado } \\
\text { para expressar a } \\
\text { linguagem }\end{array}$ \\
\hline ILs & $\begin{array}{l}\text { Como é o nome } \\
\text { de sua filha? }\end{array}$ & & \\
\hline OJ & Paqui ó. Paqui. & $\begin{array}{c}\text { Aponta para a sua boca e } \\
\text { sinaliza com as mãos que não } \\
\text { consegue falar. }\end{array}$ & Gesto \\
\hline ILs & $\begin{array}{l}\text { Você quer tentar } \\
\text { escrever? }\end{array}$ & & \\
\hline OJ & Hum & $\begin{array}{c}\text { Balança a cabeça e faz } \\
\text { expressão facial indicando } \\
\text { dúvida } \\
\end{array}$ & $\begin{array}{c}\text { Gesto e expressão } \\
\text { facial e com os olhos. }\end{array}$ \\
\hline ILs & Tente vai & & \\
\hline RECORTE & & & \\
\hline
\end{tabular}

Lucélia Teixeira Santos Santana, aluna do curso de Letras Modernas da UESB e Bolsista de Iniciação Científica do CNPq.

Imagem 1 - Escrita de OJ

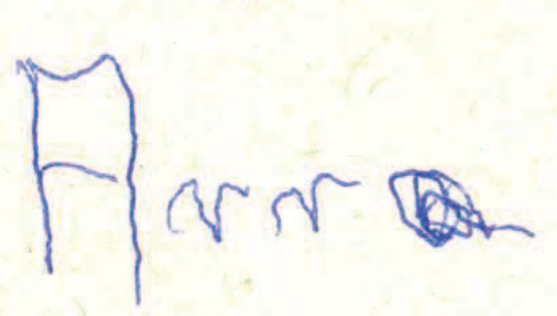

Nesse sentido, ao (re)construir a sua escrita e a possibilidade de desenhar com a mão esquerda, OJ reconstrói a sua linguagem. Há uma ressignificação da modalidade escrita: uma saída para as dificuldades enfrentadas na oralidade, um vetor que direciona a reconstituição da 
oralidade e ressignifica a linguagem para o sujeito. Na interação, marcas da subjetividade de OJ são projetadas para o exterior, visto que a subjetividade designa a consciência interior de si, somente o sujeito tem acesso a essa interioridade, em oposição à objetividade do mundo externo que pensamos ser acessível a todos. Essas marcas são reveladas na constância em demonstrar a angústia de não falar o que quer, no quadro 4, após a leitura da agenda de OJ, a investigadora toma conhecimento de uma viagem que OJ fará e começa indagar sobre sua viagem. Observem a vontade de falar e o processo alternativo encontrado por ele no recorte apresentado a seguir.

Situação comunicativa: Sessão 22-02-2012

Quadro 4 - Dado 5 “Amanhã” e Dado 6 gestos para: a palavra está aqui, mas não sai

\begin{tabular}{|c|c|c|c|}
\hline $\begin{array}{l}\text { Sigla do } \\
\text { locutor }\end{array}$ & Transcrição & $\begin{array}{l}\text { Observação sobre } \\
\text { as condições de } \\
\text { produção de processos } \\
\text { alternativos de } \\
\text { produção não verbais }\end{array}$ & $\begin{array}{l}\text { Observação sobre } \\
\text { as condições de } \\
\text { produção de processos } \\
\text { alternativos de } \\
\text { produção verbais }\end{array}$ \\
\hline Ics & $\begin{array}{c}\text { Quando que você } \\
\text { vai viajar? }\end{array}$ & & \\
\hline OJ & Silêncio & & \\
\hline Ics & $\begin{array}{l}\text { Quando você vai } \\
\text { viajar? A... }\end{array}$ & & $\begin{array}{l}\text { Oferece a ele o } \\
\text { prompting “a” }\end{array}$ \\
\hline Ics & $\begin{array}{l}\text { Vamo lá. Vou } \\
\text { perguntar de novo. } \\
\text { Quando você } \\
\text { vai viajar? A... }\end{array}$ & & $\begin{array}{l}\text { Oferece o prompting } \\
\text { “a” novamente. }\end{array}$ \\
\hline OJ & $\begin{array}{c}\text { A-mã - (...) -nhã é } \\
\text { pá ... }\end{array}$ & $\begin{array}{c}\text { Aponta para a própria } \\
\text { boca tentando dizer que } \\
\text { a palavra não sai }\end{array}$ & \\
\hline Ils & Mas saiu jóia. Saiu! & & \\
\hline RECORTE... & & & \\
\hline
\end{tabular}

Reconhecemos, por meio desse dado, que OJ não apresenta problemas de compreensão, mas que tem dificuldades de iniciativa. Porém, quando lhe é oferecido o prompting "a” ele consegue responder à pergunta de Ics, “amanhã”, mesmo com certa dificuldade. Nas primeiras sessões de acompanhamento do sujeito OJ, ele pronunciava poucas palavras como “Não" e "tá bom”, realizava também uma espécie de estereotipia que ainda é realizada, mas com menos frequência "paquí-ó”. Após oito (8) meses de acompanhamento, aproximadamente, dezesseis (16) sessões em grupo e dez (10) individuais, percebemos o progresso desse sujeito. OJ está usando um maior número de palavras para se comunicar e também utilizando outros sistemas de significação, recorrendo frequentemente aos gestos, para se fazer entender, como no dado 6 acima, quando utiliza o gesto para preencher a lacuna da palavra que não vinha naquele momento. 


\section{Considerações finais}

Verificamos que nas situações comunicativas e eventos comunicativos em que se engajam os sujeitos com lesões cerebrais no ECOA, a língua(gem) apresenta-se constitutivamente incompleta, falha e heterogênea, características da ordem própria e estrutural da língua quando usada também pelos sujeitos sem lesões cerebrais, e que, em meio as instabilidades e as práticas significativas, organizadas em torno de situações cotidianas que propiciam a atividade efetiva de linguagem em uma atuação conjunta entre sujeitos e pesquisadores, há eficácia nas interações visto que "há linguagem na afasia quando há sujeito" (COUDRY, 2002, p. 102), aquele que "tem um trabalho para exercer com/na/sobre a linguagem em relação ao(s) outro(s) e ao mundo (re)organizado” (COUDRY, 2002, p. 102). Nesse sentido, acreditamos na potencialidade do sujeito estar na linguagem, mesmo quando abaladas as propriedades essenciais da linguagem.

\section{Referências}

AROUX, S. (1996) A linguagem humana. In: A filosofia da linguagem. Trad. José Horta Nunes. Campinas: Editora da UNICAMP, 1998

BENVENISTE, E. (1970). O aparelho formal da enunciação. In: Problemas de Linguística Geral II. São Paulo: Pontes. 1989.

(1963) Vista d'olhos sobre o desenvolvimento da Linguística. In: Problemas de Linguística geral I. 4 ed. Campinas, SP: Pontes, Editora da Universidade Estadual de Campinas. 1995.

COUDRY, M. I. H. Caminhos da Neurolinguística Discursiva: o velho e o novo. In: Caminhos da Neurolinguística Discursiva: teorização e práticas com a linguagem. Coudry, M. I. H.; Freire, F. M. P.; Andrade, M. L. F.; Silva, M. A. (org.). Campinas (SP): Mercado de Letras.

. Linguagem e Afasia: Uma abordagem discursiva da Neurolinguística. In: Cadernos de Estudos Linguísticos, 42, Campinas, IEL, UNICAMP, 99-129. 2002.

Pressupostos teóricos e dinâmica de funcionamento do Centro de Convivência de Afásicos (CCA). Mesa Redonda: Aspectos neuropsicológicos e discursivos: Centro de Convivência de Afásicos (CCA). In: IV Congresso Brasileiro de Neuropsicologia. Sociedade Brasileira de Neurologia, Rio de Janeiro, R.J. 1999.

.10 anos de Neurolinguística no IEL. In: Cadernos de Estudos Linguísticos, 32: p. 09-23, 1997.

O que é dado em Neurolinguística? In: PEREIRA DE CASTRO, M. F. C. (org.), $O$ método e o dado no estudo da linguagem. Campinas: Editora da UNICAMP. 1996. 
. Linguística e Neurolinguística. In: DAMASCENO, B. P. \& COUDRY, M. I. Hadler (org.), Temas de Neuropsicologia e Neurolinguística, V. 4. São Paulo: SBNp. 1995.

Neuropsicologia: Aspectos biológicos e sociais. In: Temas em Neuropsicologia e Neurolinguística - Vol. I (38-57). RODRIGUES, N. \& MANSUR, L. L. (eds.). São Paulo: Tec Art. 1993.

COUDRY, M. I. H. Fontes de postulados discursivos no estudo das afasias. Cadernos de Estudos Linguísticos, 22, 167-171. Campinas, IEL/ UNICAMP. 1992.

. (1986). Diário de Narciso: Discurso e Afasia. São Paulo: Martins Fontes. 1988.

COUDRY, M. I. H.; MORATO, E. M. A ação reguladora da interlocução e de operações epilinguísticas sobre objetos linguísticos. In: Cadernos de Estudos Linguísticos, 15, 117-135. Campinas, IEL/UNICAMP, 1988.

COUDRY, M. I. H.; SAMPAIO, N. F. S.; ISHARA, C. (Org.) Estudos da Língua(gem): Estudos em Neurolinguística. Vol. 6, No. 2. UESB: Vitória da Conquista, BA, 2008. 285p.

COUDRY, M.I.H.; MORATO, E. M. (1991). Processos de significação: a visão neurolinguística. In: Anais da ABRALIN, 13, 59-67.

COUDRY, M.I.H.; POSSENTI, S. Avaliar discursos patológicos. In: Cadernos de Estudos Linguísticos, 5, 99-109. Campinas, IEL/ UNICAMP.1983.

FEDOSSE, E. Processos alternativos de significação de um poeta afásico. Campinas, 2008. Tese (Doutorado em Linguística) Instituto de Estudos da Linguagem, Universidade Estadual de Campinas.

Da relação linguagem e praxia: estudo neurolinguístico de um caso de afasia. Campinas, 2000. Dissertação (Mestrado em Linguística) Instituto de Estudos da Linguagem, Universidade Estadual de Campinas.

FREIRE, F. M. P. Agenda Mágica: linguagem e memória. Campinas, 2005. Tese (Doutorado em Linguística), Instituto de Estudos da Linguagem, Universidade Estadual de Campinas.

FRANCHI, C. Linguagem: Atividade constitutiva:. In: Almanaque, 5. São Paulo: Brasiliense. 1977.

FREUD, S. (1891) A interpretação das afasias. Tradução de Ramón Alcalde. Buenos Aires: Ediciones Nueva Visión, 1973.

ISHARA, C. A-fa-si-a: um sujeito em cena. Campinas, 2008. Tese (Doutorado em Linguística) Instituto de Estudos da Linguagem, Unicamp. 
JAKOBSON, R. Dois aspectos da linguagem e dois tipos de afasia. In: Linguística e Comunicação. 7. ed. São Paulo, Cultrix, 1974.

NOVAES, T. P.; COTA I. R.; SANTANA, L. T. S.; ALMEIDA, D. P.; SAMPAIO, N. F. S. Estudos da parafasia em situações dialógicas com MB. In: Anais da 64 ${ }^{\text {a. }}$ Reunião Anual da SBPC. 2012.

SAMPAIO, N. F. S. Uma abordagem sociolinguística da afasia: o Centro de Convivência de Afásicos (Unicamp) como uma Comunidade de Fala em Foco. Campinas, 2006. 175 p. Tese (Doutorado em Linguística), Instituto de Estudos da Linguagem, Universidade Estadual de Campinas,

SAUSSURE, F. (1916). Curso de Linguística Geral. São Paulo: Editora Cultrix, 1990. 